\title{
Syntaxin Modulation of Calcium Channels in Cortical Synaptosomes As Revealed by Botulinum Toxin C1
}

\author{
Jeremy B. Bergsman ${ }^{1,2}$ and Richard W. Tsien ${ }^{2}$ \\ ${ }^{1}$ Neurosciences Program, and ${ }^{2}$ Department of Molecular and Cellular Physiology, Beckman Center, Stanford University \\ School of Medicine, Stanford, California 94305
}

When the presynaptic membrane protein syntaxin is coexpressed in Xenopus oocytes with $\mathrm{N}$ - or $\mathrm{P} / \mathrm{Q}$-type $\mathrm{Ca}^{2+}$ channels, it promotes their inactivation (Bezprozvanny et al., 1995; Wiser et al., 1996, 1999; Degtiar et al., 2000) (I. B. Bezprozvanny, P. Zhong, R. H. Scheller, and R. W. Tsien, unpublished observations). These findings led to the hypothesis that syntaxin influences $\mathrm{Ca}^{2+}$ channel function in presynaptic endings, in a reversal of the conventional flow of information from $\mathrm{Ca}^{2+}$ channels to the release machinery. We examined this effect in isolated mammalian nerve terminals (synaptosomes). Botulinum neurotoxin type $\mathrm{C} 1$ (BoNtC1), which cleaves syntaxin, was applied to rat neocortical synaptosomes at concentrations that completely blocked neurotransmitter release. This treatment altered the pattern of $\mathrm{Ca}^{2+}$ entry monitored with fura-2. Whereas the initial $\mathrm{Ca}^{2+}$ rise induced by depolarization with $\mathrm{K}^{+}$-rich solution was unchanged, late $\mathrm{Ca}^{2+}$ entry was strongly augmented by syntaxin cleavage. Similar results were obtained when $\mathrm{Ca}^{2+}$ influx arose from repetitive firing induced by the $\mathrm{K}^{+}$-channel blocker 4-aminopyridine. Cleavage of vesicleassociated membrane protein with BoNtD or SNAP-25 with BoNtE failed to produce a significant change in $\mathrm{Ca}^{2+}$ entry. The BoNtC1-induced alteration in $\mathrm{Ca}^{2+}$ signaling was specific to voltage-gated $\mathrm{Ca}^{2+}$ channels, not $\mathrm{Ca}^{2+}$ extrusion or buffering, and it involved N-, P/Q- and R-type channels, the high voltageactivated channels most intimately associated with presynaptic release machinery. The modulatory effect of syntaxin was not immediately manifest when synaptosomes had been $\mathrm{K}^{+}$predepolarized in the absence of external $\mathrm{Ca}^{2+}$, but developed with a delay after admission of $\mathrm{Ca}^{2+}$, suggesting that vesicular turnover may be necessary to make syntaxin available for its stabilizing effect on $\mathrm{Ca}^{2+}$ channel inactivation.

Key words: synaptosome; syntaxin; calcium channel; SNARE; synapse; synaptic vesicle; modulation; clostridium botulinum; toxin; neurotoxin; conotoxin; agatoxin; rat
Voltage-gated $\mathrm{Ca}^{2+}$ channels convert the action potential depolarization into a $\mathrm{Ca}^{2+}$ signal that in turn triggers vesicular neurotransmitter release. The triggering event is remarkably rapid and effective; its efficient achievement requires that calcium channels and the fusion machinery be held together in close proximity (Llinás et al., 1981). Indeed, $\mathrm{Ca}^{2+}$ channels have the capability of directly binding to soluble $N$-ethylmaleimide-sensitive factor (NSF) attachment protein (SNAP) receptor (SNARE) proteins, putative components of the vesicular fusion complex (Sheng et al., 1994; Rettig et al., 1996; Charvin et al., 1997). These include a vesicular (v) SNARE, vesicle-associated membrane protein (VAMP), also known as synaptobrevin, another vesicular protein-synaptotagmin - as well as syntaxin and SNAP-25, two target membrane ( $\mathrm{t}$ ) SNAREs. The interactions with the $\mathrm{v}$ - and t-SNARES are most clear for the $\alpha_{1}$ subunits of N- and P/Q-type channels, the types of voltage-sensitive $\mathrm{Ca}^{2+}$ channels (VSCCs) that are most important for fast neurotransmitter release at nerve terminals in the mammalian CNS. When isolated from rat forebrain, a majority of $\mathrm{N}$ - and $\mathrm{P} / \mathrm{Q}$-type channels appear associated with SNARE proteins (el Far et al., 1995; Martin-Moutot et al.,

Received June 22, 1999; revised March 29, 2000; accepted March 29, 2000.

This work was supported by the Silvio Conte-National Institute of Mental Health Center for Neuroscience Research, the Mathers Charitable Trust, and the McKnight Foundation. We thank D. G. Nicholls for generous assistance with synaptosome preparation and the glutamate release assay and M. E. Adams for the gift of AgaIVB. We are grateful to I. B. Bezprozvanny, V. E. Degtiar, G. S. Pitt, R. H. Scheller, and S. M. Smith for helpful discussions.

Correspondence should be addressed to Dr. Richard W. Tsien, Department of Molecular and Cellular Physiology, Beckman Center B105, Stanford University Medical Center, Stanford, CA 94305-5345. E-mail: rwtsien@leland.stanford.edu. Copyright (C) 2000 Society for Neuroscience $0270-6474 / 00 / 204368-11 \$ 15.00 / 0$
1996; Pupier et al., 1997; Vance et al., 1999). The channelSNARE protein interaction may be susceptible to regulation (Sheng et al., 1996, 1997; Kim and Catterall, 1997; Yokoyama et al., 1997).

The existence of physical interactions between $\mathrm{Ca}^{2+}$ channels and SNARE proteins raises an intriguing possibility: in addition to the mechanism whereby $\mathrm{Ca}^{2+}$ influx triggers secretion, originally proposed by Katz and Miledi (1965) and Douglas (1968), can the secretory machinery also exert an influence on $\mathrm{Ca}^{2+}$ influx? The idea of such a counterflow of information was suggested independently for two different proteins: cysteine string proteins, which were proposed to signal the presence of a docked vesicle to the $\mathrm{Ca}^{2+}$ channel (Mastrogiacomo et al., 1994), and syntaxin, whose overexpression was found to reduce $\mathrm{Ca}^{2+}$ influx in Aplysia neurons (Smirnova et al., 1995). Subsequently, heterologous coexpression of syntaxin, SNAP-25, or synaptotagmin with either N- or P/Q- type (and in some cases, L- type) VSCCs in Xenopus oocytes was shown to affect channel activity (Bezprozvanny et al., 1995; Wiser et al., 1996, 1999; Degtiar et al., 2000). Effects of coexpression of SNAP-25 and a specific isoform of $\alpha_{1 \mathrm{~A}}$ have also been seen in HEK 293 cells (Zhong et al., 1999). Syntaxin was also found to be required for G-protein modulation of $\mathrm{Ca}^{2+}$ channels in calyciform presynaptic terminals in chick ciliary ganglia (Stanley and Mirotznik, 1997).

These intriguing observations prompted us to ask whether such interactions occur in functional mammalian nerve terminals. To investigate the regulation of $\mathrm{Ca}^{2+}$ influx by specific SNARE proteins, we have measured fluorimetrically $\mathrm{Ca}^{2+}$ changes and glutamate release in synaptosomes and tested effects of various 
clostridial neurotoxins, proteases which selectively cleave SNARE proteins (Montecucco and Schiavo, 1995). The results provided evidence that syntaxin exerts a significant influence on $\mathrm{Ca}^{2+}$ influx through $\mathrm{N}$-, $\mathrm{P} / \mathrm{Q}$ - and R-type channels in mammalian nerve terminals.

\section{MATERIALS AND METHODS}

Synaptosome preparation. Synaptosomes were prepared essentially as described (McMahon et al., 1992). Brains from two or three 6- to 8 -week-old Sprague Dawley rats were homogenized in $\sim 20 \mathrm{ml}$ of ice-cold $0.32 \mathrm{M}$ sucrose in a Potter-Elvehjem (Teflon glass) tissue homogenizer driven at 400-500 $\mathrm{rpm}$. This suspension was diluted to a final volume of $\sim 20 \mathrm{ml}$ per brain with more ice-cold sucrose and centrifuged at $3000 \times$ $g$ for 3 min at $4^{\circ} \mathrm{C}$. Sufficient dilution of synaptosomes was important to prevent clumping. The supernatant was centrifuged at $14,600 \times g$ for 12 $\min$ at $4^{\circ} \mathrm{C}$. The upper layers of the pellets formed were resuspended in $\sim 2 \mathrm{ml}$ of ice-cold sucrose per brain used. Before use synaptosomes were washed by 1:2 dilution with basal buffer (BB) (in mM: $\mathrm{NaCl} 140, \mathrm{KCl} 5$, $\mathrm{MgCl}_{2}$ 1, $\mathrm{NaHCO}_{3}$ 5, HEPES pH 7.420 , glucose 10, $0.2 \mu \mathrm{m}$ filtered) and resuspended in the medium of choice. A sample of each synaptosome preparation was washed and solubilized in $0.15 \%$ SDS for the determination of protein concentration using the BCA kit (Pierce, Rockford, IL) with BSA as a standard.

Features common to all experiments. All dye and clostridial toxin treatment was done in bulk for the day's experiments as described below. Dye loading preceded toxin treatment. After any dye loading and/or clostridial toxin treatment, synaptosomes were washed by pelleting and resuspension in the appropriate buffer. After the final treatment, synaptosomes were washed and resuspended at $2 \mathrm{mg} / \mathrm{ml}$ in BB. This suspension was aliquoted into single run amounts $(2 \mathrm{mg}$ for glutamate release and $1 \mathrm{mg}$ for $\mathrm{Ca}^{2+}$ measurements) and stored on ice. Such aliquots were spun down and resuspended in $2 \mathrm{ml}$ of prewarmed experimental buffer and allowed to equilibrate to $36-37^{\circ} \mathrm{C}$ for $4 \mathrm{~min}$ in the continuously stirred, heated cuvette holder of the spectrofluorimeter immediately before each experiment. In all experiments, the cuvette contained 0.63 mM EGTA, along with any $\mathrm{Ca}^{2+}$ channel blockers or other drugs during the 4 min warming period. To produce the free $\mathrm{Ca}^{2+}$ levels indicated in the text, $\mathrm{CaCl}_{2}$ was added in amounts calculated by the Maxchelator software, version 6.50, using the Bers constants (Chris Patton, Stanford University, Pacific Grove, CA). Fluorescence measurements were made in a Perkin-Elmer (Norwalk, CT) LS50B spectrofluorimeter using the Perkin-Elmer FLDM software. Data were exported in ASCII format.

Calcium indicator loading. Synaptosomes to be used for $\mathrm{Ca}^{2+}$ measurements for a given day were suspended at $2 \mathrm{mg} / \mathrm{ml}$ in loading buffer (LB; BB with $1.3 \mathrm{mM} \mathrm{Ca}^{2+}$ and $50 \mathrm{mg} / \mathrm{ml} \mathrm{BSA} ; 0.2 \mu \mathrm{m}$ filtered). The synaptosomes were loaded with fura-2 AM dissolved in DMSO (or Magfura-2 AM in some experiments not shown) at a final concentration of $10 \mu \mathrm{M}$ (final [DMSO] $=0.5 \%$ ) for $45 \mathrm{~min}$ at $37^{\circ} \mathrm{C}$.

Clostridial toxin treatment. Synaptosomes to be treated with clostridial toxins were suspended at $2 \mathrm{mg} / \mathrm{ml}$ in LB. Toxins were normally used at the following concentrations: botulinum neurotoxin type $\mathrm{C} 1$ (BoNtC1) $66 \mathrm{~nm}$, BoNtD $110 \mathrm{~nm}$, BoNtE $110 \mathrm{~nm}$, and BoNtC3 $1.67 \mu \mathrm{g} / \mathrm{ml}$. All lots of BoNtC1, BoNtD, and BoNtE used were tested and were found to completely block $\mathrm{Ca}^{2+}$-dependent glutamate release at these concentrations. Toxin treatment was at $37^{\circ} \mathrm{C}$ for $45 \mathrm{~min}$. In some experiments indicated in the text, BoNtD and BoNtE were used at $220 \mathrm{~nm}$, and treatment was for $120 \mathrm{~min}$. Control synaptosomes in toxin experiments received mock treatments in parallel that differed only in that toxin was not added. In heat-treated toxin controls, toxin was diluted to twice its final concentration in $\mathrm{BB}$ and held at $95^{\circ} \mathrm{C}$ for $45 \mathrm{~min}$. This was cooled and combined with synaptosomes at $4 \mathrm{mg} / \mathrm{ml}$ in LB (yielding the identical toxin and synaptosome concentrations used in the other experiments) and incubated at $37^{\circ} \mathrm{C}$ for $45 \mathrm{~min}$.

Calcium flux measurement and corrections. In control experiments we found that our dye-loaded synaptosomes contained dye in one or more compartments that were inaccessible even after treatment with digitonin $(18 \mathrm{mg} / \mathrm{ml})$ or ionomycin $(100 \mu \mathrm{M})$, compared to treatment with SDS $(0.1 \%)$, as well as one or more compartments that allowed voltageindependent $\mathrm{Ca}^{2+}$ fluxes (Fig. $2 A$; see below). This compartmentalization was very similar between fura- 2 and magfura- 2 and was not dependent on the dye concentration during loading (data not shown). Our experiments indicated that the inaccessible dye was not in synaptosomal cytosol (Fig. $2 A$, inset; see below). Some of this dye was $\mathrm{Ca}^{2+}$-bound, and some was $\mathrm{Ca}^{2+}$-free because the direction of the fluorescence change on
SDS treatment after previous digitonin or ionomycin treatment was $\left[\mathrm{Ca}^{2+}\right]_{0}$-dependent. The similar results with the indicators of different $\mathrm{Ca}^{2+}$ affinities suggested that the dye resided in at least two compartments and that each compartment had either very high or very low $\left[\mathrm{Ca}^{2+}\right]$ relative to the dissociation constants of the indicators. Under these conditions, application of the equation used by Grynkiewicz et al. (1985) to calculate $\left[\mathrm{Ca}^{2+}\right]$ was inappropriate, because one of its assumptions is that all dye molecules are experiencing the same $\left[\mathrm{Ca}^{2+}\right]$. Additionally, nerve terminals have very high concentrations of endogenous $\mathrm{Ca}^{2+}$ buffers (Fontana and Blaustein, 1993) that would skew the relationship between our parameter of interest, $\mathrm{Ca}^{2+}$ influx, and free $\left[\mathrm{Ca}^{2+}\right]$. For these two reasons, we chose to use relatively heavy fura-2 loading and to use the change in fluorescence normalized by the baseline fluorescence at the beginning of the experiment as a measure of accumulated $\mathrm{Ca}^{2+}$ influx (Neher and Augustine, 1992; Neher, 1995). Because this method only required measuring at one wavelength, it also had the benefit of allowing faster sampling rates. The principal concerns when not using ratiometric methods are dye photobleaching and changes in path length. We determined in control experiments that bleaching was not significant on the time scale of our experiments (data not shown). Changes in path length are not of concern in a stirred cuvette.

We measured $\mathrm{Ca}^{2+}$ influx by monitoring the fluorescence at $505 \mathrm{~nm}$ from excitation at $382 \mathrm{~nm}$, sampled once per $0.6 \mathrm{sec}$. Background fluorescence from an equivalent sample of synaptosomes not loaded with dye was recorded at the beginning of the experiments of each day and subtracted from all subsequent readings. When drugs that affected fluorescence readings, such as nimodipine, were used, background readings taken with the drug present were subtracted from the experimental results. Note that experiments with and without such compounds may not be compared quantitatively. Background fluorescence was typically $<10 \%$ of the total signal. After background subtraction, each trace was normalized to the average fluorescence during its $15 \mathrm{sec}$ baseline. Fluorescence decreases at $382 \mathrm{~nm}$, signifying increases in $\left[\mathrm{Ca}^{2+}\right]$, are plotted upwards in the figures.

Characterization and correction of the depolarization-independent calcium signal. We presumed that the depolarization-independent signal that resulted from the addition of $\mathrm{Ca}^{2+}$ alone seen in Figure $2 \mathrm{~A}$ was $\mathrm{Ca}^{2+}$ equilibrating into some compartment that contained fura- 2 but had its $\mathrm{Ca}^{2+}$ depleted during the 4 min incubation in EGTA. If this compartment was separate from the synaptosomal cytosolic compartment, we wanted to subtract the change of fluorescence attributable to $\mathrm{Ca}^{2+}$ entering this compartment to reveal the true size of any change in the signal that resulted from influx through voltage-gated $\mathrm{Ca}^{2+}$ channels into synaptosomes. We therefore investigated the nature of this compartment.

In principle, a depolarization-independent signal might result from the binding of added $\mathrm{Ca}^{2+}$ to fura- 2 that had leaked out of the synaptosomes or other structures into the incubation medium. This was not the case because (1) the signal was only about two-thirds saturated by the addition of $10 \mu \mathrm{M} \mathrm{Ca}^{2+}$ (which is $\sim 50$ times the $K_{\mathrm{d}}$ of fura- 2 for $\mathrm{Ca}^{2+}$ ) and (2) none of the signal returned quickly to baseline after the addition of sufficient EGTA to lower the free $\left[\mathrm{Ca}^{2+}\right]$ to $<10 \mathrm{~nm}$ (unlike free fura-2, which released its bound $\mathrm{Ca}^{2+}$ within the few seconds mixing time of our equipment; data not shown). Therefore this fura- 2 was trapped in some compartment that exchanges $\mathrm{Ca}^{2+}$ with the external medium with some resistance.

Because the entry of $\mathrm{Ca}^{2+}$ into the compartment containing this fura-2 was not depolarization-dependent, we presumed that it does not represent flux through VSCCs into synaptosomes. To confirm this, we performed several control experiments with known blockers of VSCCs. The depolarization-independent $\mathrm{Ca}^{2+}$ signal was not significantly changed $(p>0.38)$ when external $\mathrm{Ca}^{2+}$ was added in the combined presence of blockers of L-type $(10 \mu \mathrm{M}$ nimodipine), N-type $[1 \mu \mathrm{M}$ $\omega$-conotoxin GVIA (GVIA)], and P/Q-type [1 $\mu \mathrm{M} \omega$-agatoxin or $1 \mu \mathrm{M}$ $\omega$-conotoxin MVIIC (MVIIC)] $\mathrm{Ca}^{2+}$ channels (data not shown). This ruled out the possibility of a flux through $\mathrm{Ca}^{2+}$ channels that were somehow open even in resting synaptosomes.

We next considered the possibility that the depolarizationindependent $\mathrm{Ca}^{2+}$ signal might arise from $\mathrm{Na}^{+} / \mathrm{Ca}^{2+}$ antiport. This was not the case because exposure to $50 \mu \mathrm{M}$ Bepridil, an inhibitor of the $\mathrm{Na}^{+} / \mathrm{Ca}^{2+}$ antiporter (Kleyman and Cragoe, 1988), did not affect the $\mathrm{Ca}^{2+}$ signal that resulted from the $\mathrm{Ca}^{2+}$ addition (data not shown). We also tested the idea that the $\mathrm{Ca}^{2+}$ signal might arise from flux into or out of mitochondria or other $\mathrm{Ca}^{2+}$ stores: when the protocol was performed after preincubation $(4 \mathrm{~min})$ and in the continued presence of $1 \mu \mathrm{M}$ thapsigargin (an inhibitor of a $\mathrm{Ca}^{2+}$ store $\mathrm{Ca}^{2+}$-ATPase) or $3 \mu \mathrm{M}$ 
carbonyl cyanide $p$-(triflouromethoxy)phenyl-hydrazone (FCCP) (a protonophore that causes discharge of mitochondrial $\mathrm{Ca}^{2+}$ stores), the signal was unchanged compared to that in the absence of drug (data not shown). (The experiments using FCCP were performed by exciting fluorescence at $340 \mathrm{~nm}$ instead of $382 \mathrm{~nm}$ because FCCP has a strong absorbance peak at the latter wavelength.) Finally, if the depolarizationindependent signal resulted from $\mathrm{Ca}^{2+}$ binding to fura- 2 in the synaptosomal cytosol, given the magnitude of the signal we would expect that such $\mathrm{Ca}^{2+}$ should have caused some neurotransmitter release. When we measured glutamate release caused by $\mathrm{Ca}^{2+}$ addition without depolarization, no increase above the small background release rate was seen (Fig. 2A, inset).

Because the depolarization-independent signal resulted from $\mathrm{Ca}^{2+}$ binding to fura- 2 in a pool that was separate from the one in which we were interested, we have subtracted the depolarization-independent signal from all traces shown except those in Figure 2. To not introduce noise from the subtraction, we subtracted smooth curves that were fit to the average depolarization-independent signals from the experiments of each day. The curves had no theoretical significance and consisted of a flat baseline that changed to the sum of two exponentials plus a sloping line at the time of $\mathrm{Ca}^{2+}$ addition. Curves were fit by minimizing least square differences with Microsoft Excel, version 7.0a. Such a subtraction in the fluorescence domain is valid when comparing fluorescence changes if and only if the subtracted fluorescence signal arises outside the dye pool of interest. Depolarization-independent signals were collected for each experimental condition and were not found to be significantly different for any experimental condition tested. Approximately equal numbers of depolarization-independent and depolarization-dependent signals were measured each day in each condition.

Importance of preincubation conditions for detection of $\mathrm{Ca}^{2+}$ influx modulation. In our initial efforts, we failed to detect an effect of BoNtC1 on $\mathrm{Ca}^{2+}$ influx in synaptosomes, despite complete inhibition of $\mathrm{Ca}^{2+}$ dependent release (Bergsman and Tsien, 1996). We discovered that an effect of BoNtC1 was revealed if the resting $\left[\mathrm{Ca}^{2+}\right]$ in the synaptosomes were lowered with a preincubation in a solution with a free $\mathrm{Ca}^{2+}$ concentration $<10 \mathrm{nM}$. We confirmed that preincubation in $\mathrm{Ca}^{2+}$. containing medium eliminated the syntaxin effect by varying the interval between $\mathrm{Ca}^{2+}$ and $\mathrm{KCl}$ addition between $3.5 \mathrm{sec}$ (the shortest interval we were able to implement) and $25 \mathrm{sec}$. When $\mathrm{Ca}^{2+}$ was applied for 25 sec before the stimulus, BoNtC1-treated synaptosomes displayed a $\mathrm{Ca}^{2+}$ rise that was not significantly different than that in control synaptosomes $(p>0.25)$.

Glutamate release measurement and corrections. Glutamate release was monitored essentially as described (Nicholls et al., 1987). Released glutamate was detected as an increase in the fluorescence at $460 \mathrm{~nm}$, with excitation at $340 \mathrm{~nm}$, caused by the production of NADPH from $\mathrm{NADP}^{+}$, coupled to the oxidation of the released glutamate to 2-oxoglutarate by glutamate dehydrogenase (GDH). Two milligrams of synaptosomes were suspended in $2 \mathrm{ml}$ of $\mathrm{BB}$ made up to $1 \mathrm{~mm} \mathrm{NADP}^{+}$. One hundred units of GDH were added immediately before the start of data collection. A reading of the background fluorescence of the synaptosomes and any $\mathrm{NADP}^{+} / \mathrm{NADPH}$ was taken at the start of each run and subtracted from subsequent measurements.

The data from glutamate release experiments were corrected for the lag of the enzyme in NADPH production by a program written for this purpose. The kinetics of the response of the system to a pulse of glutamate added at the end of each run were used to backcalculate the amount of unconverted glutamate for a given rate of NADPH production. This value was added to the raw NADPH data, and the result was converted from fluorescence to amount of glutamate based on the amplitude of the response to the glutamate standard. Although the data were collected and displayed every $0.6 \mathrm{sec}$, the correction algorithm filters the data to $\sim 8 \mathrm{sec}$ resolution.

Statistics. Statistical differences were assayed on the average of the last $10 \mathrm{sec}$ of each trace using a two-tailed $t$ test assuming unequal variances. Calculations were performed with Microsoft Excel, version 7.0a using the data analysis add-in.

Materials. Clostridial toxins were from Wako USA (Richmond, VA). The VSCC blockers GVIA, AgaIVA, and MVIIC were from Peptide Institute (Osaka, Japan). AgaIVB was a generous gift from Michael Adams (University of California, Riverside, CA). L-AP-4 was from Tocris (Ballwin, MO). Nimodipine, (+) $\alpha$-methyl-4-carboxyphenylglycine (MCPG), and thapsigargin were from Research Biochemicals (Natick, MA). Glutamate dehydrogenase, staurosporine, ionomycin, and NADP ${ }^{+}$ were from Calbiochem (La Jolla, CA). Fura-2 AM and Magfura-2 AM were from Molecular Probes (Eugene, OR). Cuvettes were UV-grade acrylic and were from Denville Scientific (Metuchen, NJ). Western analysis was done according to standard protocols and detected with the ECL kit (Amersham, Buckinghamshire, UK). Other reagents were from Fluka (Buchs, Switzerland), Aldrich (Milwaukee, WI), or Sigma (St. Louis, MO) and were of at least American Chemical Society grade where applicable.

\section{RESULTS}

\section{Cleaving syntaxin with botulinum toxin $\mathrm{C} 1$ increases calcium influx}

To determine whether syntaxin influences $\mathrm{Ca}^{2+}$ channels in nerve terminals, we looked for an effect of BoNtC1, which cleaves syntaxin, on $\mathrm{Ca}^{2+}$ entry in rat cortical synaptosomes (Fig. $1 \mathrm{~A}$ ). $\mathrm{Ca}^{2+}$ entry was evoked by successive application of $1 \mathrm{mM} \mathrm{CaCl}_{2}$ and $60 \mathrm{~mm} \mathrm{KCl}, 3.5 \mathrm{sec}$ apart to fura-2-loaded synaptosomes. The synaptosomes were preincubated in nominally $0 \mathrm{Ca}^{2+}$ external solution (see Materials and Methods), an important experimental feature for the results that follow. Because N- and P/Q-type channels are the main putative targets of syntaxin action (Bezprozvanny et al., 1995), experiments were performed in the presence of $10 \mu \mathrm{M}$ nimodipine to block L-type channels unless otherwise specified. Figure $1 A$ compares depolarization-dependent fluorescence signals recorded from synaptosomes that had been pretreated with $\mathrm{BoNtC} 1$ with signals taken from control synaptosomes, not treated with toxin. Traces from three separate runs are shown in each case, and the signals have been corrected for the depolarization-independent signal caused by addition of $\mathrm{Ca}^{2+}$ without $\mathrm{K}^{+}$(Fig. 2A). As a result of depolarizationinduced opening of $\mathrm{Ca}^{2+}$ channels, the control traces rose rapidly to a peak before progressively decaying over the next $60 \mathrm{sec}$. The $\mathrm{Ca}^{2+}$ signals from three parallel runs with BoNtC1-treated synaptosomes showed an early rise nearly identical to the control traces, but decayed much more slowly and to a lesser extent. Thus, the impact of the toxin pretreatment grew progressively larger over the course of the depolarization. This effect was not observed when synaptosomes were pretreated with heatinactivated BoNtC1 (Fig. 1B): in this case, no significant alteration of the depolarization-induced $\mathrm{Ca}^{2+}$ transients was observed $(p>0.4)$. In separate experiments, we verified that pretreatment with the heat-inactivated toxin failed to cleave syntaxin or to block $\mathrm{Ca}^{2+}$-dependent glutamate release, effects clearly evident with BoNtC1 (data not shown).

\section{The effect of BoNtC1 is specific to depolarization- induced $\mathrm{Ca}^{2+}$ entry}

We performed additional control experiments to find out whether BoNtCl acted on pathways for $\mathrm{Ca}^{2+}$ equilibration, distinct from voltage-dependent $\mathrm{Ca}^{2+}$ channels. Figure $2 A$ illustrates the depolarization-independent $\mathrm{Ca}^{2+}$ rise that was produced by exposing the synaptosomal preparation to $1 \mathrm{mM} \mathrm{CaCl}_{2}$ without subsequent addition of $60 \mathrm{~mm} \mathrm{KCl}$. Parallel experiments showed that this fluorescence signal arose from $\mathrm{Ca}^{2+}$ uptake into a compartment distinct from functional synaptosomes (see Materials and Methods). The uptake process was unresponsive to inhibitors of known $\mathrm{Ca}^{2+}$ transport pathways and was not associated with any detectable glutamate release (Fig. $2 A$, inset). As shown in Figure $2 A$, the depolarization-independent $\mathrm{Ca}^{2+}$ rise was not significantly affected by BoNtC1 $(p>0.4)$. Corrections have been made for the depolarization-independent $\mathrm{Ca}^{2+}$ rise in all other figures (see Materials and Methods for details).

Another series of experiments tested for an effect of syntaxin cleavage on the performance of $\mathrm{Ca}^{2+}$ buffering and extrusion 
A

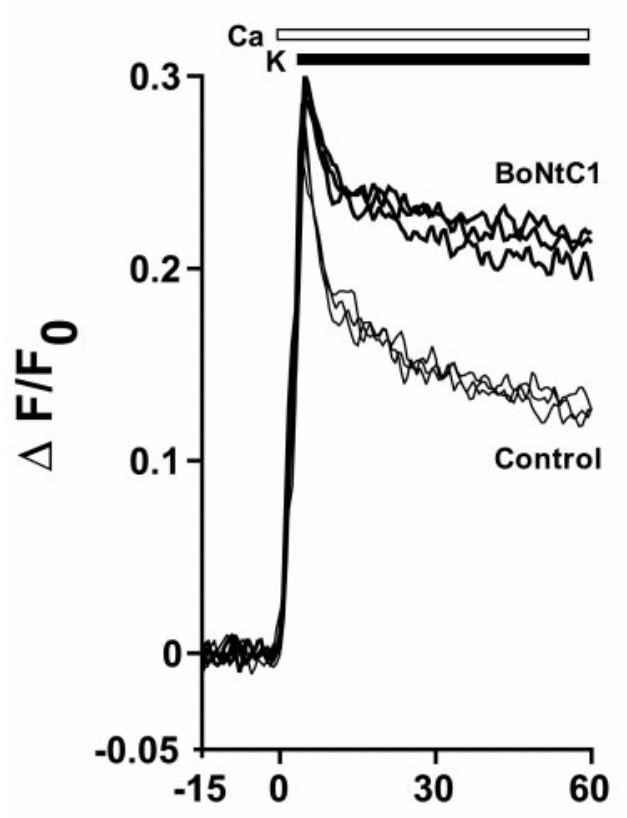

B

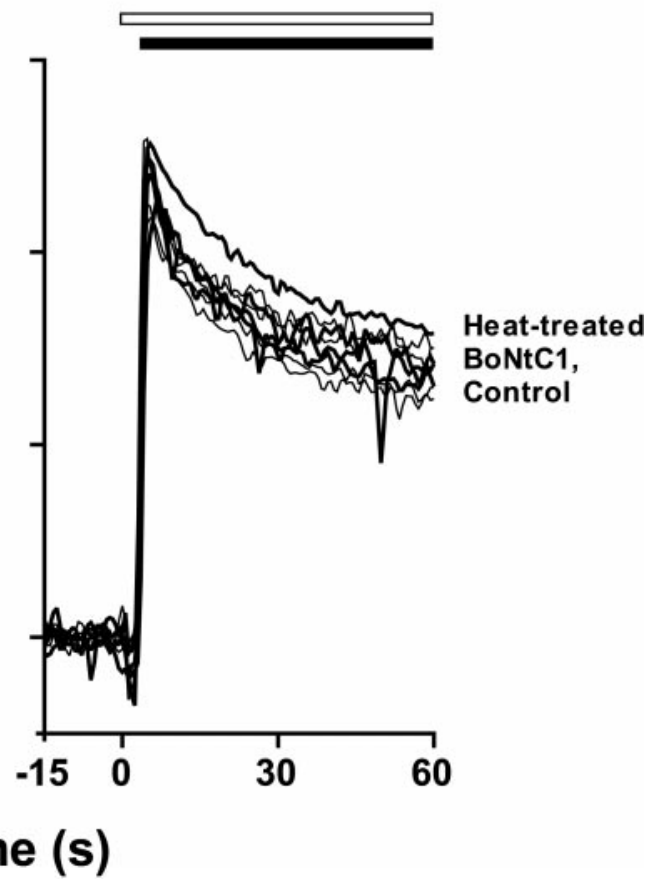

Figure 1. BoNtC1 treatment increases $\mathrm{Ca}^{2+}$ influx. A, Fura-2-loaded synaptosomes were either mock-treated $(\mathrm{Control})$ or pretreated with $66 \mathrm{~nm}$ BoNtC1 $\left(\right.$ BoNtC1) for $45 \mathrm{~min}$ at $37^{\circ} \mathrm{C}$. At time $t=0$ external free $\mathrm{Ca}^{2+}$ was raised to $1 \mathrm{~mm}$. At $t=3.5$ sec external $\mathrm{K}^{+}$was raised to 60 mM. Horizontal bars mark times of additions. Ordinate indicates the fractional decrease in fluorescence relative to baseline, signifying elevated $\mathrm{Ca}^{2+}$. A $10 \mu \mathrm{M}$ concentration of nimodipine was present throughout to block L-type $\mathrm{Ca}^{2+}$ channels. Data have been corrected for the depolarization-independent signal (see Materials and Methods). Three runs from one synaptosome preparation are depicted under each condition. In all figures, thick traces denote toxin-treated synaptosomes, and thin traces denote mock-treated synaptosomes. $B$, Same conditions as in $A$ except BoNtC1 was incubated for 45 min at $95^{\circ} \mathrm{C}$ before application to synaptosomes. Data show four runs for each condition ( 2 runs from each of 2 synaptosome preparations).

mechanisms. These are undoubtedly recruited once intrasynaptosomal $\mathrm{Ca}^{2+}$ has been elevated by voltage-gated $\mathrm{Ca}^{2+}$ entry. Figure $2 B$ shows the protocol we used to focus on $\mathrm{Ca}^{2+}$ restorative processes. At different intervals after the introduction of $\mathrm{KCl}$ to depolarize the synaptosomes ( 3.5 or $25 \mathrm{sec}$ ), sufficient EGTA was added to the cuvette to return external free $\left[\mathrm{Ca}^{2+}\right]$ to a level below $10 \mathrm{~nm}$. In the virtual absence of external $\mathrm{Ca}^{2+}$, $\mathrm{Ca}^{2+}$ entry through voltage-dependent channels must cease, leaving only processes of $\mathrm{Ca}^{2+}$ buffering and extrusion. As expected, the averaged fluorescence signal after EGTA addition (traces labeled "EGTA") declined much more rapidly than the signal that included the contribution of continuing $\mathrm{Ca}^{2+}$ channel influx ("no EGTA"). This indicated that $\mathrm{Ca}^{2+}$ influx into the synaptosomes continued over the entire course of the prolonged depolarization, as previously reported (McMahon and Nicholls, 1991).

As shown in Figure $2 C$, pretreating the synaptosomes with BoNtC1 had no effect on the $\mathrm{Ca}^{2+}$ signal recorded after EGTA addition. Thus, cleavage of syntaxin did not affect the $\mathrm{Ca}^{2+}$ buffering and extrusion that followed the initial $\mathrm{Ca}^{2+}$ rise. An incremental effect of BoNtC1 pretreatment was only seen when depolarization-induced $\mathrm{Ca}^{2+}$ entry was allowed to continue.

\section{The BoNtC1-induced increase in $\mathrm{Ca}^{2+}$ influx does not result from block of glutamate release}

We considered the idea that BoNtC1 treatment might increase $\mathrm{Ca}^{2+}$ influx by blocking neurotransmitter release, thereby relieving $\mathrm{Ca}^{2+}$ channels from feedback inhibition via presynaptic receptors. This possibility gains plausibility with knowledge that glutamatergic nerve terminals greatly outnumber presynaptic ter- minals containing other neurotransmitters, (Verhage et al., 1991, 1995; McMahon et al., 1992) and activation of metabotropic glutamate receptors (mGluRs) is known to downregulate non-Ltype $\mathrm{Ca}^{2+}$ channels. Accordingly, we tested whether the BoNtC1 effect persisted when $\mathrm{Ca}^{2+}$ influx was evoked in the presence of a group III mGluR agonist (30 $\mu \mathrm{M} \mathrm{L-AP-4)} \mathrm{or} \mathrm{a} \mathrm{general} \mathrm{mGluR}$ antagonist ( 0.75 or $1.5 \mathrm{~mm}+\mathrm{MCPG})$. Neither agent caused a significant change in the magnitude or time course of the BoNtC1 effect (data not shown). If anything, +MCPG slightly decreased $\mathrm{Ca}^{2+}$ influx, in the opposite direction from what would be expected from feedback via $\mathrm{mGluR}$ receptors. Additional evidence against secondary effects of blocking neurotransmitter release was derived from experiments with other clostridial neurotoxins (see below).

\section{Modification of voltage-gated $\mathrm{Ca}^{2+}$ influx is specific to BoNtC1}

It was of interest to compare the effect of BoNtC1 with that of other clostridial neurotoxins. Figure $3 A$ shows pooled results for the effect of BoNtC1, obtained from five independent synaptosome preparations (13 BoNtC1 trials and 10 control trials). The averaged data show once again that the toxin pretreatment did not alter the magnitude of the $\mathrm{Ca}^{2+}$ increase over the first few seconds but produced a highly significant increase in late $\mathrm{Ca}^{2+}$ influx $(p<0.001)$.

A potential complication in experiments with BoNtC1 is the possibility of contamination of the toxin preparation with a related molecule, BoNtC3, an ADP ribosyltransferase, that might be isolated from the same organism in trace amounts. This cannot 

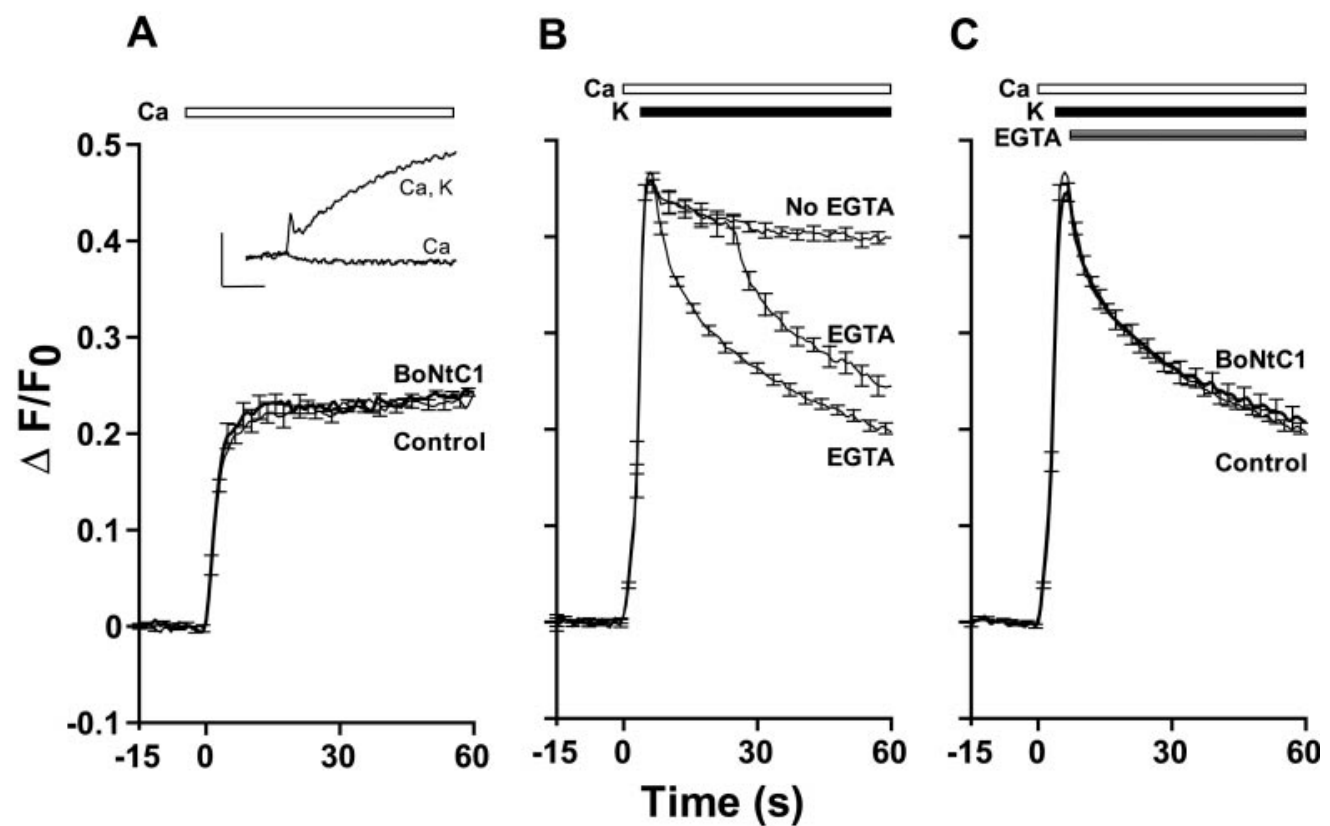

Figure 2. Analysis of $\mathrm{Ca}^{2+}$ channel-independent $\mathrm{Ca}^{2+}$ fluxes. $A$, Effect of BoNtC1 on response to elevating external $\mathrm{Ca}^{2+}$. $\mathrm{Ca}^{2+}$ was added to fura-2-loaded synaptosomes at $t=0 \mathrm{sec}$ without elevation of external $\mathrm{K}^{+}$. Traces are averages of five or more runs from two synaptosome preparations. Inset, $\mathrm{Ca}^{2+}$-dependent glutamate release caused by raising $\mathrm{Ca}^{2+}$ only $(\mathrm{Ca})$ compared with release caused by raising $\mathrm{Ca}^{2+}$ at $t=0$ followed by elevated $\mathrm{K}^{+}$at $t=3.5 \mathrm{sec}(\mathrm{Ca}, \mathrm{K})$. Both release signals were corrected for $\mathrm{Ca}^{2+}$-independent release and for enzyme lag (Materials and Methods). Vertical scale bar, $10 \mathrm{nmol}$ of glutamate per milligram of synaptosomal protein; horizontal scale bar, $100 \mathrm{sec}$. B. Distinction between $\mathrm{Ca}^{2+}$ influx and $\mathrm{Ca}^{2+}$ buffering and extrusion. Control fura-2-loaded synaptosomes. $\mathrm{Ca}^{2+}$ and $\mathrm{K}^{+}$were elevated at $t=0$ and $t=3.5$ sec, respectively. In the bottom traces (EGTA), EGTA was elevated at either $t=7 \mathrm{sec}$ (lowest trace) or $25 \mathrm{sec}$ (middle trace). EGTA elevation lowered external free Ca ${ }^{2+}$ to $<10 \mathrm{nM}^{2}$ EGTA was not elevated in the top trace (No EGTA). Means \pm SEM of four or more runs from two or more synaptosome preparations. $C$, Effect of BoNtC1 on Ca ${ }^{2+}$ buffering and extrusion. $\mathrm{Ca}^{2+}$ and $\mathrm{K}^{+}$were elevated at $t=0$ and $t=3.5 \mathrm{sec}$, respectively, and EGTA was elevated at $t=7 \mathrm{sec}$, reducing external free $\mathrm{Ca}^{2+}$ to $<10 \mathrm{nM}$. Means \pm SEM of eight or more runs from four or more synaptosome preparations. A $10 \mu \mathrm{M}$ concentration of nimodipine was present in all experiments shown in this figure. No correction for depolarization-independent $\mathrm{Ca}^{2+}$ signal in any of the panels (in contrast to other figures).

be completely excluded even though according to the manufacturer, Wako Chemicals, the commercially available preparation of BoNtC1 toxin appeared as a single band on disk-PAGE. Accordingly, we tested BoNtC3 at a dose that would allow for up to 5\% contamination of the BoNtC1 preparation. Even at this relatively high concentration, BoNtC3 produced no significant effect on the intracellular $\mathrm{Ca}^{2+}$ transient (Fig. $\left.3 B\right)(p>0.3)$ and no detectable effect on $\mathrm{Ca}^{2+}$-dependent glutamate release (Fig. $3 F$ ).

\section{Cleavage of VAMP or SNAP-25 does not affect calcium influx}

Syntaxin is but one of several SNARE proteins known to be involved in vesicle docking and fusion in presynaptic terminals. Other SNARE proteins include SNAP-25 and VAMP. Because SNAP-25 and VAMP have been found to engage in direct binding interactions with voltage-sensitive $\mathrm{Ca}^{2+}$ channels (el Far et al., 1995; Rettig et al., 1996; Sheng et al., 1996; Kim and Catterall, 1997), it was of considerable interest to test for possible modulatory effects on $\mathrm{Ca}^{2+}$ channel activity. Accordingly, we asked whether $\mathrm{Ca}^{2+}$ influx might be modified by cleaving VAMP with botulinum toxin D or SNAP-25 with botulinum toxin E (Niemann et al., 1994). (Unfortunately, no neurotoxin is available to cleave synaptotagmin.) Both of these toxins cleaved their expected targets at terminals capable of $\mathrm{Ca}^{2+}$-dependent glutamate release, as shown by their complete block of such release (Fig. $3 G, H$ ). However, the depolarization-induced $\mathrm{Ca}^{2+}$ transient was not affected by pretreatment of the synaptosomes with BoNtD (Fig. $3 C ; p>0.5$ ) or by BoNtE pretreatment (Fig. $3 D ; p>0.7$ ).
Western analysis of toxin-treated synaptosomes showed only partial cleavage of syntaxin, SNAP-25, and VAMP (data not shown), in accord with previous reports (Schiavo et al., 1992, 1995; Blasi et al., 1993a,b; Williamson et al., 1996; Capogna et al., 1997; Raciborska et al., 1998). Various possibilities that might account for the partial cleavage are as follows. The SNARE proteins might be present in intact synaptosomes, but sequestered in a noncycling pool that is uncleavable by BoNts. Alternatively, they may be trapped as heterotrimeric complexes resistant to BoNt cleavage if they were in metabolically inactive synaptosomes in which NSF would be inoperative. Finally, SNARE proteins may be present in lysed synaptosomes and unsealed membrane fragments that are unable to produce or retain the toxin light chain. The latter possibilities would not affect our conclusions because they involve structures that would not participate in either transmitter release or $\mathrm{Ca}^{2+}$ influx. Because we could not be certain about the basis for the incomplete cleavage, we proceeded to examine the effects of more aggressive toxin treatment, just to be on the safe side. Doses of BoNtD or BoNtE threefold higher than those used to produce an effect with BoNtC1, applied for periods lasting over twice as long, still failed to produce an effect on $\mathrm{Ca}^{2+}$ influx (data not shown). The lack of effect of BoNtE is particularly notable, because it excludes the possibility that BoNtC1 might have acted merely through cleavage of SNAP-25 rather than syntaxin (Foran et al., 1996; Williamson et al., 1996; Capogna et al., 1997). The lack of effect of either BoNtD or BoNtE rules out the idea that the action of BoNtC1 is secondary to blockade of exocytosis (see above); if this were the case, each of 
A
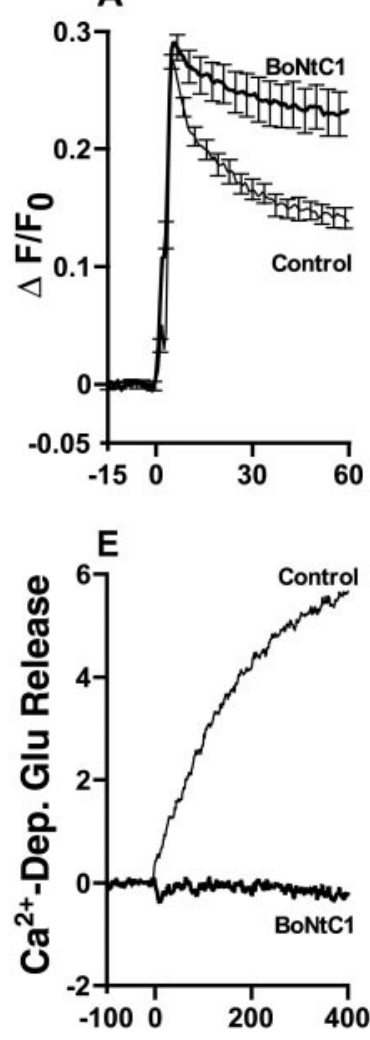

B

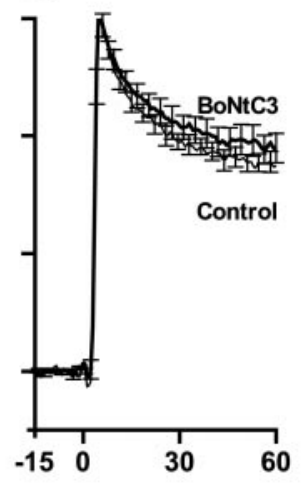

$\mathrm{F}$

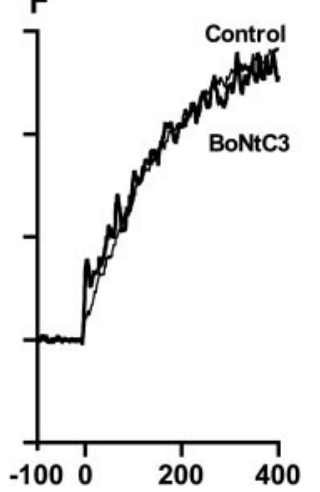

c

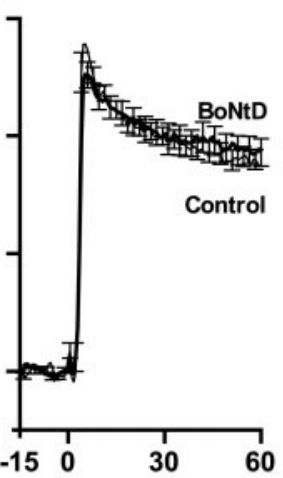

G

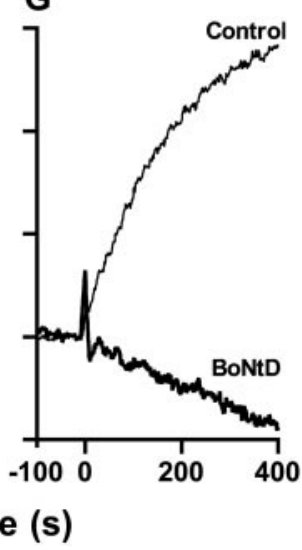

D
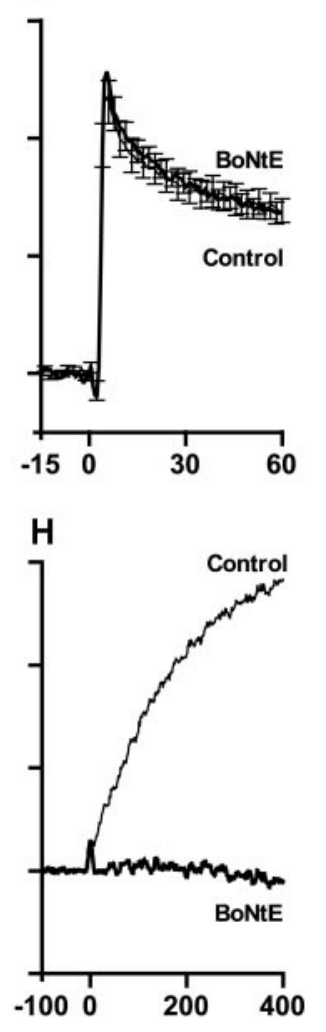

Figure 3. Differential effect of various clostridial neurotoxins on $\mathrm{Ca}^{2+}$ influx. Synaptosomes were treated with various clostridial toxins and tested for altered $\mathrm{Ca}^{2+}$ influx. $\mathrm{Ca}^{2+}$ and $\mathrm{K}^{+}$were elevated at $t=0$ and $t=3.5 \mathrm{sec}$, respectively. A $10 \mu \mathrm{M}$ concentration of nimodipine was present throughout all experiments shown in this figure. $A$, Effect of pretreatment with BoNtC1 (66 nM), mean $\pm \mathrm{SEM}$ of $\geq 10$ runs from five synaptosome preparations, including the data shown in Figure $1 A$. B, Effect of pretreatment with BoNtC3 $(1.67 \mu \mathrm{g} / \mathrm{ml})$, mean \pm SEM of six runs from two synaptosome preparations; $C$, Effect of pretreatment with BoNtD $(110 \mathrm{nM})$, mean \pm SEM of six or more runs from two synaptosome preparations; $D$, Effect of pretreatment with BoNtE $(110 \mathrm{nM})$, mean \pm SEM of six runs from two synaptosome preparations. $E-H$, $\mathrm{Ca}^{2+}$-dependent glutamate release after treatment with the same toxins as in $A-D$, respectively. Release was corrected for $\mathrm{Ca}^{2+}$-independent release and for the enzyme lag (Materials and Methods) and was expressed as nanomoles of glutamate per milligram of synaptosomal protein. Note difference in time scale from $A$ to $D$. Negative $\mathrm{Ca}^{2+}$-dependent release in $G$ results from BoNtD block of $\mathrm{Ca}^{2+}$-independent release as well as $\mathrm{Ca}^{2+}$-dependent release, a consistent finding.

the clostridial toxins that block neurotransmitter release would be expected to have similar effects, contrary to what was observed.

\section{Identification of $\mathrm{Ca}^{2+}$ channel types susceptible to modulation by syntaxin}

The results presented so far (Figs. 1-3) apply to all non-L-type channels pooled together. To discriminate further among the individual channel types, additional pharmacological dissection of $\mathrm{Ca}^{2+}$ influx was performed using channel-specific toxins against a constant background of L-type blockade (Fig. $4 B-D$ ). Figure $4 B$ shows $\mathrm{Ca}^{2+}$ entry signals evoked in the presence of AgaIVB $(1 \mu \mathrm{M})$, a potent blocker of $\mathrm{P} / \mathrm{Q}$-type channels that largely spares N-type channels (Adams et al., 1993; Teramoto et al., 1993) (M. Cataldi, personal communication). Under these conditions, the ability of BoNtC1 to modify $\mathrm{Ca}^{2+}$ influx remained significant $(p<0.05)$ and was retained to at least the same degree (61\% increase) as that found when the $\mathrm{P} / \mathrm{Q}$-type channels were full contributors to the $\mathrm{Ca}^{2+}$ signal (56\% increase; Fig. 4A) (changes measured over the last $10 \mathrm{sec}$ of the $60 \mathrm{sec}$ exposure to high $\left.\mathrm{K}^{+}\right)$. Likewise, the BoNtC1 effect persisted $(p<0.001)$ when N-type channels were blocked with $0.5 \mu \mathrm{M}$ GVIA (Fig. $4 C$ ), although it was smaller than when N-type channels were not blocked (38 vs 56\%). Reports of significant R-type current
(Randall and Tsien, 1995) in some rat central nerve terminals (Meder et al., 1997; Newcomb et al., 1998; Wu et al., 1998) prompted us to test for effects of cleaving syntaxin on this type of $\mathrm{Ca}^{2+}$ influx. Figure $4 D$ shows $\mathrm{Ca}^{2+}$ signals obtained with both $\mathrm{N}$ - and $\mathrm{P} / \mathrm{Q}$-type channels blocked under the combined influence of $0.5 \mu \mathrm{M}$ GVIA $+1 \mu \mathrm{M} \omega$-conotoxin MVIIC (once again under conditions of L-type channel blockade). The $\mathrm{Ca}^{2+}$ signal supported by the remaining R-type channels reached a peak only approximately one-third as large as that produced by all non-L type channels together. Nevertheless, the BoNtC1 effect on this influx was rather large ( $112 \%$ increase; $p<0.01)$. Taken together, these results suggest that R-type channels, like other non-L-type channels, are capable of responding to syntaxin cleavage.

In addition to testing the effect of BoNtC1 on non L-type channels, we specifically looked for an effect of the toxin under conditions in which L-type channels made a prominent contribution to the synaptosomal $\mathrm{Ca}^{2+}$ entry. Synaptosomes were exposed to GVIA $(0.5 \mu \mathrm{M})$ and MVIIC $(1 \mu \mathrm{M})$, which should block N-type and N-, P-, and Q-type channels respectively, sparing Land R-type channels (Fig. 4D). The remaining $\mathrm{Ca}^{2+}$ influx stimulated by $\mathrm{KCl}$ depolarization was minimally affected by BoNtC1, resulting in a $30 \%$ increase that was not significantly different 


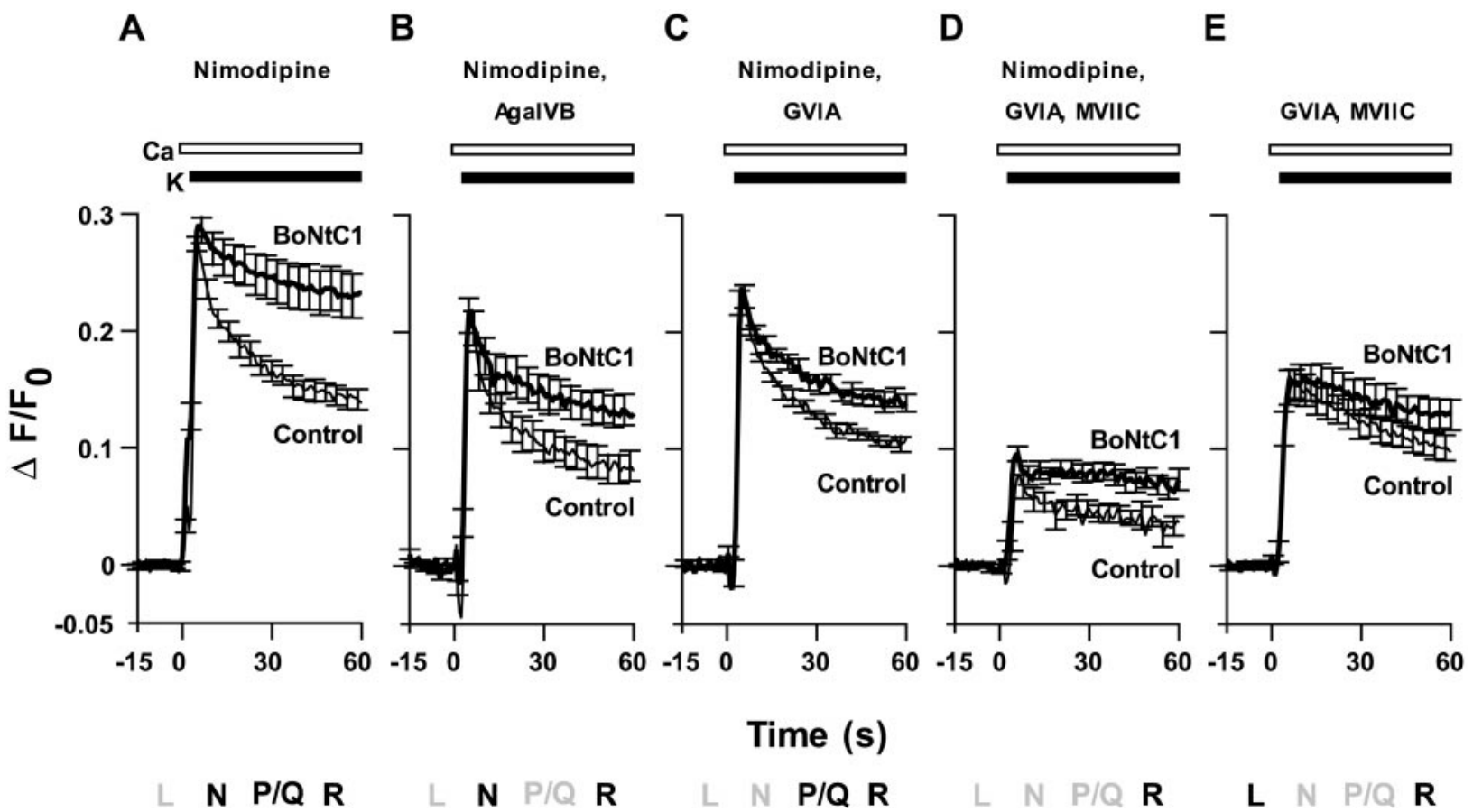

Figure 4. Effect of syntaxin cleavage on various $\mathrm{Ca}^{2+}$ channels. The effect of BoNtC1 treatment in the presence of various $\mathrm{Ca}{ }^{2+}$ channel blockers. $A$, A $10 \mu \mathrm{M}$ concentration of nimodipine. Mean \pm SEM of $\geq 10$ runs from five synaptosome preparations. $B$, A $10 \mu \mathrm{M}$ concentration of nimodipine and 1 $\mu \mathrm{M}$ AgaIVB. Mean \pm SEM of six runs from two synaptosome preparations. $C$, A $10 \mu \mathrm{M}$ concentration of nimodipine and $0.5 \mu \mathrm{M}$ GVIA. Mean \pm SEM of six runs from two synaptosome preparations. $D$, A $10 \mu \mathrm{M}$ concentration of nimodipine, $0.5 \mu \mathrm{M}$ GVIA, and $1 \mu \mathrm{M}$ MVIIC. Mean \pm SEM of six runs from two synaptosome preparations. $E$, A $0.5 \mu \mathrm{M}$ concentration of GVIA and $1 \mu \mathrm{M}$ MVIIC. Mean \pm SEM of nine or more runs from three synaptosome preparations. Because of optical effects of nimodipine, the magnitude of the signals in this panel are not directly comparable with those in other panels of this or other figures. Note that panel $A$ repeats the data shown in Figure $3 A$, for the sake of comparison to $B-D$.

$(p>0.1)$, attributable in part to larger variability in these experiments. It is possible that any impact of BoNtC1 under these conditions arose from the responsiveness of a minority fraction of unblocked R-type channels, although we cannot exclude an additional small effect of syntaxin on L-type channels themselves. The overall conclusion is that syntaxin cleavage affects $\mathrm{N}$-type and R-type channels most prominently, exerts a milder effect on $\mathrm{P} / \mathrm{Q}$-type channels, and gives little or no effect on L-type channels.

\section{BoNtC1 reveals syntaxin effect on $\mathrm{Ca}^{2+}$ influx stimulated by 4-aminopyridine}

A critical series of experiments tested whether the influence of syntaxin extended to $\mathrm{Ca}^{2+}$ influx stimulated by methods other than direct $\mathrm{K}^{+}$-depolarization. We used the $\mathrm{K}^{+}$channel inhibitor 4-aminopyridine (4-AP), which blocks certain voltage-gated $\mathrm{K}^{+}$ channels and thereby causes spontaneous, TTX-sensitive repetitive firing in synaptosomes (Tibbs et al., 1989, 1996). Figure 5 shows the $\mathrm{Ca}^{2+}$ signal evoked by stimulating synaptosomes with 2 mm 4-AP and the effect of BoNtC1. 4-AP produced a sustained rise in synaptosomal free $\mathrm{Ca}^{2+}$ concentration somewhat smaller than that evoked by high $\mathrm{K}^{+}$(Tibbs et al., 1989). Pretreatment with BoNtC1 caused a significant increase in the steady level of $\mathrm{Ca}^{2+}(p<0.002)$, very much like that found with high $\mathrm{K}^{+}$ stimulation. On a percentage basis, the BoNtC1-mediated increase was at least as large with 4 -AP $(63 \%)$ as it was with $\mathrm{K}^{+}$ stimulation (56\%). If anything, the incremental difference in the $\mathrm{Ca}^{2+}$ signal in treated and untreated synaptosomes developed more rapidly with 4-AP stimulation, reaching its maximum value after $\sim 15 \mathrm{sec}$, whereas this difference continued to develop for at least $30 \mathrm{sec}$ with $\mathrm{K}^{+}$stimulation. The magnitude of the difference and the speed of its development may be accounted for by the kinetic properties of the syntaxin inhibition as studied with cloned $\mathrm{N}$-type $\mathrm{Ca}^{2+}$ channels $\left(\alpha_{1 \mathrm{~B}}\right)$ in Xenopus oocytes (Degtiar et al., 2000). In comparison to maintained depolarizations, repeated brief depolarizations (akin to the activity thought to be induced by 4-AP) are not only more efficient in inducing inactivation of $\mathrm{Ca}^{2+}$ channels (Patil et al., 1998) but also more effective in allowing syntaxin to exert its inactivation-promoting effect (see Discussion). An additional possibility is that 4-AP induced $\mathrm{Ca}^{2+}$ entry through a somewhat different mixture of $\mathrm{Ca}^{2+}$ channel types than that stimulated by $\mathrm{K}^{+}$elevation.

\section{Time course of the action of syntaxin}

The absence of an immediate effect is noteworthy in light of our previous findings in Xenopus oocytes (Bezprozvanny et al., 1995; Degtiar et al., 2000). These results showed that free syntaxin decreased the availability of $\mathrm{N}$ - and $\mathrm{P} / \mathrm{Q}$-type $\mathrm{Ca}^{2+}$ channels over a wide range of membrane potentials, probably spanning the resting potential of the synaptosomes. Thus, if syntaxin were free to interact with $\mathrm{Ca}^{2+}$ channels, we would have expected a decrease in $\mathrm{Ca}^{2+}$ influx immediately after $\mathrm{K}^{+}$-depolarization, very like that seen in oocyte recordings of $\mathrm{Ca}^{2+}$ channel current. In contrast, there was a striking absence of any immediate effect with either high $\mathrm{K}^{+}$or 4-AP stimulation. We considered three possible explanations of the delayed effect. In one scenario, cleavage of syntaxin by previously internalized BoNtC1 light chain would await activation of the release machinery. This interpretation seems highly unlikely in light of our finding that glutamate release is completely blocked by the standard toxin pretreatment, with no hint of a brief burst of release followed by no release, as would be expected for delayed cleavage by toxin. In a second scenario, 


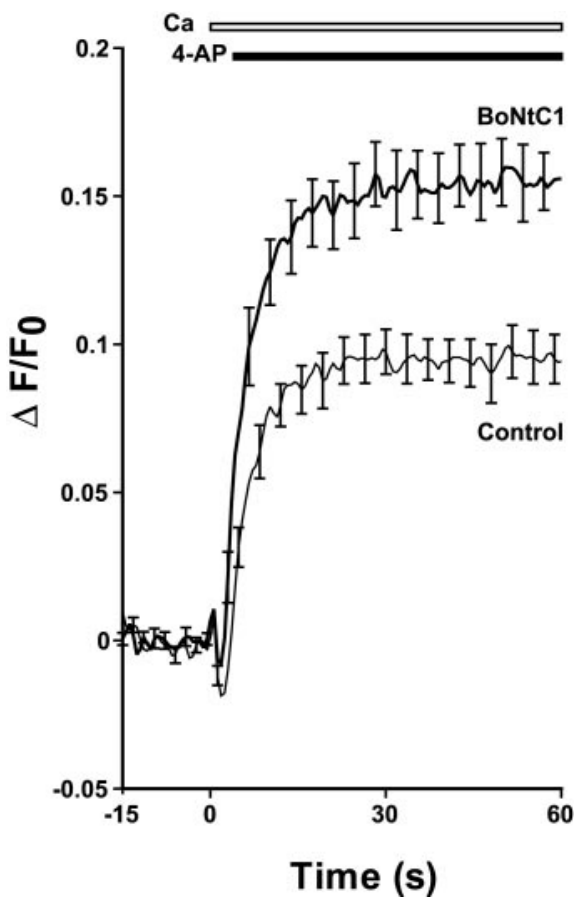

Figure 5. BoNtC1 effect on $\mathrm{Ca}^{2+}$ influx induced by repetitive firing. At $t=0$ external free $\mathrm{Ca}^{2+}$ was raised to $1 \mathrm{~mm}$. At $t=3.5 \mathrm{sec}, 2 \mathrm{~mm}$ 4-aminopyridine was added as a depolarizing agent in lieu of $60 \mathrm{mM} \mathrm{K}^{+}$. Mean \pm SEM of six runs from two synaptosome preparations. A $10 \mu \mathrm{M}$ concentration of nimodipine was present throughout.

synaptosomal $\mathrm{Ca}^{2+}$ channels would undergo voltage-dependent inactivation at relatively depolarized potentials, so that syntaxin stabilization of inactivation would only be asserted after external $\mathrm{K}^{+}$had been elevated. Finally, it seemed possible that the syntaxin in synaptic terminals would not be free at first to modulate the $\mathrm{Ca}^{2+}$ channels, but would only become capable of channel modulation as a consequence of the progressive vesicular turnover that follows depolarization-induced $\mathrm{Ca}^{2+}$ entry (Bezprozvanny, Zhong, Scheller, and Tsien, unpublished observations). To distinguish between these latter two possibilities, we applied a strong predepolarization in the absence of $\mathrm{Ca}^{2+}$, to increase the degree of channel inactivation before assaying $\mathrm{Ca}^{2+}$ entry. Synaptosomes were exposed to $60 \mathrm{mM} \mathrm{K}^{+}$, low $\mathrm{Ca}^{2+}$ solution for either 3.5 (Fig. $6 A$ ) or $60 \mathrm{sec}$ (Fig. $6 B$ ) before admission of $\mathrm{Ca}^{2+}$. This procedure would maximize the chances of detecting an immediate effect of syntaxin if the second scenario were applicable. As expected, predepolarization significantly attenuated the initial rise in $\mathrm{Ca}^{2+}$. There was a $14 \%$ drop in peak $\mathrm{Ca}^{2+}$ level with the $60 \mathrm{sec}$ predepolarization relative to that evoked after the $3.5 \mathrm{sec}$ predepolarization (and probably an even greater decrease relative to $\mathrm{Ca}^{2+}$ transients evoked without any predepolarization; Fig. $3 A$ ). However, after either 3.5 or $60 \mathrm{sec}$ predepolarizations, there was still no significant difference between the initial $\mathrm{Ca}^{2+}$ signals with and without BoNtC1 pretreatment. The modulatory effect of syntaxin developed with a delay, just as in the experiments in which no predepolarization was imposed. This experiment excluded the second scenario, but left open the possibility that the modulatory action of syntaxin was not asserted until some event downstream of $\mathrm{Ca}^{2+}$ entry had taken place, vesicular turnover being a likely possibility.

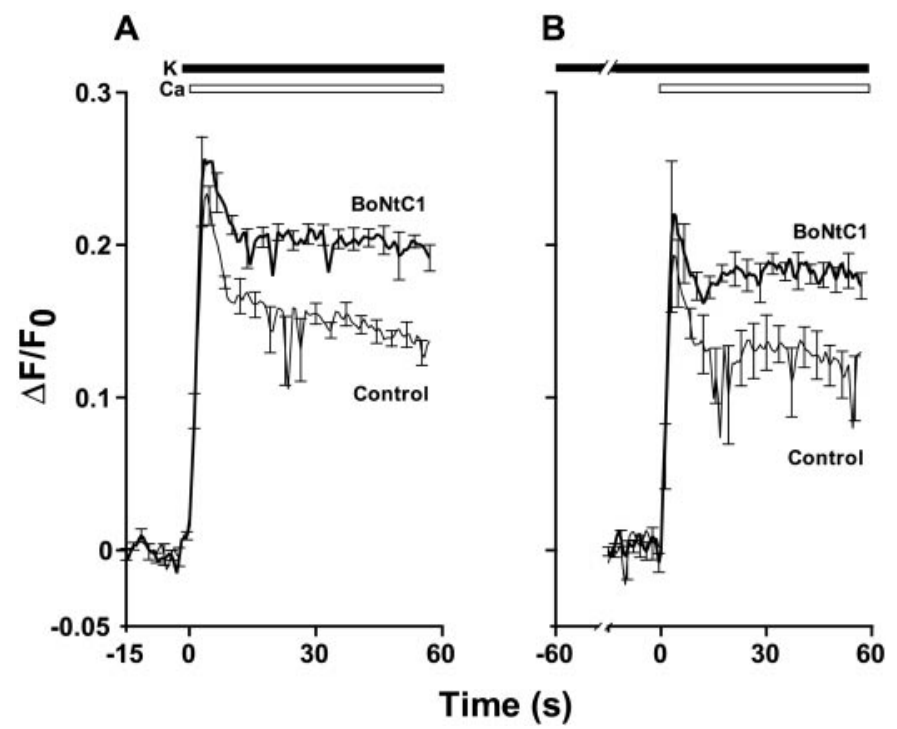

Figure 6. BoNtC1 effect on $\mathrm{Ca}^{2+}$ influx after a predepolarization. Synaptosomes were predepolarized by elevating $\mathrm{K}^{+}$before elevating $\mathrm{Ca}^{2+}$ in the presence of $10 \mu \mathrm{M}$ nimodipine. $A, \mathrm{~K}^{+}$was elevated at $t=-3.5 \mathrm{sec}$, and $\mathrm{Ca}^{2+}$ was elevated at $t=0 \mathrm{sec}$. Mean \pm SEM of six runs from two synaptosome preparations. $B, \mathrm{~K}^{+}$was elevated at $t=-60 \mathrm{sec}$, and $\mathrm{Ca}^{2+}$ was elevated at $t=0 \mathrm{sec}$. Average $\pm \mathrm{SEM}$ of four or more runs from the same two synaptosome preparations as in $A$. Note axis break between $t=$ $-60 \mathrm{sec}$ and $t=-15 \mathrm{sec}$.

\section{DISCUSSION}

Our experiments have provided the first evidence that a SNARE protein can influence $\mathrm{Ca}^{2+}$ influx in vertebrate nerve terminals. Treatment of synaptosomes with BoNtC1 to cleave syntaxin caused an increase in $\mathrm{Ca}^{2+}$ entry caused by a lessened shutting off of $\mathrm{Ca}^{2+}$ channels, not an enhancement of $\mathrm{Ca}^{2+}$ extrusion. The increase in $\mathrm{Ca}^{2+}$ influx required syntaxin cleavage: neither BoNtD cleavage of VAMP nor BoNtE cleavage of SNAP-25 had any detectable effect, although all the toxins were confirmed as active by monitoring the cleavage of SNARE protein targets and the blockade of glutamate release. Based on pharmacological dissection of $\mathrm{Ca}^{2+}$ currents, this effect appeared to be greatest on the activity of $\mathrm{N}$ - and R-type channels, smaller on $\mathrm{P} / \mathrm{Q}$-type channels, and was not detectable in the case of L-type channels.

\section{Initial condition important for detection of syntaxin modulation}

The effect of BoNtC1 was seen if the synaptosomes were preincubated in nominally zero $\mathrm{Ca}^{2+}$ solution, presumably because this preserved a low initial level of $\left[\mathrm{Ca}^{2+}\right]_{i}$, but not after preincubation with $2 \mathrm{~mm}\left[\mathrm{Ca}^{2+}\right]_{\mathrm{o}}$ (see Materials and Methods). We considered the possibility that the initial $\left[\mathrm{Ca}^{2+}\right]_{\mathrm{i}}$ might influence the activity of protein kinases that can in principle interfere with the interaction between syntaxin and the $\alpha_{1}$ subunit of the $\mathrm{Ca}^{2+}$ channel (Yokoyama et al., 1997). However, when we tested effects of $10 \mu \mathrm{M} \mathrm{KN62,} \mathrm{an} \mathrm{inhibitor} \mathrm{of} \mathrm{CaMKII,} \mathrm{or} 2 \mu \mathrm{M}$ staurosporine, a relatively broad spectrum kinase inhibitor that blocks the action of PKC, we were unable to rescue the BoNtC1 effect in the face of preincubation in $\mathrm{Ca}^{2+}$-containing external solution. Thus, it remains unclear how the basal $\mathrm{Ca}^{2+}$ level regulates the effects of syntaxin on $\mathrm{Ca}^{2+}$ channels. The explanation may be important in understanding the physiological significance of the syntaxin modulation. 


\section{Comparison with previous results in other systems}

The influence of syntaxin on $\mathrm{Ca}^{2+}$ influx in nerve terminals was similar to that found for $\mathrm{Ca}^{2+}$ channel currents in syntaxinexpressing oocytes. The specificity of syntaxin for certain types of high voltage-activated channels and not others is in good agreement with that found with cloned $\mathrm{Ca}^{2+}$ channel subunits in oocytes (Bezprozvanny et al., 1995) (but see, Wiser et al., 1996, 1999). If anything, P/Q-type channels seemed less responsive to BoTxC1 in synaptosomes than expected from the earlier oocyte data, but this may reflect splice variations in $\alpha_{1 \mathrm{~A}}$ [which in some cases prevent binding to and modulation by syntaxin (Zhong et al., 1999)] or differences in the composition of ancillary subunits. Syntaxin cleavage increased synaptosomal $\mathrm{Ca}^{2+}$ influx during repetitive firing stimulated by $4-\mathrm{AP}$ at least as much as that during steady depolarizations evoked by high $\mathrm{K}^{+}$, consistent with findings with trains of brief depolarizations in oocytes (Degtiar et al., 2000). However, there was one important respect in which the influence of syntaxin in nerve terminals differed significantly from that found in the oocyte expression system. In the synaptosomes, BoNtC1 pretreatment made little difference during the first few seconds of stimulation, but only caused significantly increased $\mathrm{Ca}^{2+}$ entry after prolonged stimulation (Fig. 1). Thus, the syntaxin inhibition was not tonically enabled, but developed gradually with time. In contrast, $\mathrm{Ca}^{2+}$ channel currents in oocytes were diminished from the very beginning of a test depolarization because of decreased availability of $\mathrm{Ca}^{2+}$ channels (Bezprozvanny, Zhong, Scheller, and Tsien, unpublished observations) (Degtiar et al., 2000) spanning the -55 to $-60 \mathrm{mV}$ resting potential expected for synaptosomes (Blaustein and Goldring, 1975).

The lack of a significant BoNtC1 effect on early $\mathrm{Ca}^{2+}$ entry in the synaptosomes is consistent with previous findings in other preparations in which investigators have looked for an influence of syntaxin on $\mathrm{Ca}^{2+}$ channel currents. These systems include the squid giant synapse (Marsal et al., 1997; O’Connor et al., 1997; Sugimori et al., 1998), the presynaptic terminals of calyx synapses in chick ciliary ganglia (Stanley and Mirotznik, 1997), presynaptic terminals of Xenopus motoneurons (Rettig et al., 1997), and rat superior cervical ganglion neurons (Mochida et al., 1995, 1996). In each case, application of BoNtC1 to cleave syntaxin, or antibodies to inactivate it, failed to alter peak inward $\mathrm{Ca}^{2+}$ channel current, measured within milliseconds after application of a depolarizing voltage-clamp step. Synaptosomes are well suited for measurements of $\mathrm{Ca}^{2+}$ evoked by persistent or repetitive depolarizations, conditions that uncovered the syntaxin modulation most clearly.

\section{Syntaxin inhibition depends jointly on channel inactivation and vesicular turnover}

The progressive development of syntaxin inhibition in synaptosomes suggested that syntaxin trapping of $\mathrm{Ca}^{2+}$ channels must lag behind the depolarizing stimulus. Whereas the delay may be attributed in part to the kinetics of slow inactivation (Degtiar et al., 2000), our evidence suggests that it also depends on an event downstream of $\mathrm{Ca}^{2+}$ entry. The development of syntaxinmediated channel inhibition was delayed until after admission of external $\mathrm{Ca}^{2+}$, even in the wake of a preceding depolarization that had already promoted channel inactivation (Fig. 6). We can be reasonably sure that internal $\mathrm{Ca}^{2+}$ per se is not required for the modulatory action of syntaxin because a striking modulation of $\mathrm{Ba}^{2+}$ currents was found in oocytes even after they had been injected with high concentrations of internal divalent cation buffer (Degtiar et al., 2000). The most likely possibility that remains is that the limiting factor is the availability of syntaxin itself, which is controlled in turn by $\mathrm{Ca}^{2+}$-dependent vesicle fusion and turnover of SNARE complexes. This idea gains support from the positioning of amino acids critical for the effect of syntaxin, alanine240 and valine244 (Bezprozvanny, Zhong, Scheller, and Tsien, unpublished observations), which appear to be buried within the core of the four-helix bundle SNARE complex (Sutton et al., 1998). So long as syntaxin were sequestered in the SNARE complex by interactions with SNAP-25 and VAMP, it would remain incapable of exerting its modulatory effect. If syntaxin only became available to modulate channel activity after bouts of high activity in nerve terminals, these structures would be expected to differ from model systems such as oocytes or Aplysia neurons in which syntaxin was deliberately overexpressed. This hypothesis also provides a basis for interpreting our findings with BoNtD and E, neither of which produced a significant change in the pattern of $\mathrm{Ca}^{2+}$ influx or inactivation (Fig. 3C,D), in contrast to BoNtC1. One interpretation is that BoNtD and BoNtE prevent the fusion reaction, but somehow spare the ability of the release machinery to advance in through states in which syntaxin is available to interact with the $\mathrm{Ca}^{2+}$ channel.

\section{Comparison with published effects of vesicular depletion}

Our working hypothesis predicts that presynaptic $\mathrm{Ca}^{2+}$ channel function might be significantly affected by depletion of synaptic vesicles. Indeed, such an effect has already been demonstrated in shibire mutants of Drosophila, which undergo a temperaturesensitive block of endocytosis caused by a defect in dynamin (Kosaka and Ikeda, 1983; Ramaswami et al., 1994). $\mathrm{Ca}^{2+}$ influx at the fly neuromuscular junction was completely blocked after vesicle depletion (Umbach et al., 1998), consistent with the idea that excess syntaxin had been made available to inhibit voltagegated $\mathrm{Ca}^{2+}$ channels. It would be very interesting to see if similar results could be obtained with vesicular depletion in the synaptosomes.

\section{Physiological relevance}

The steep power-law relationship between $\mathrm{Ca}^{2+}$ influx and neurotransmitter release (Dodge and Rahamimoff, 1967) ensures that even a modest modulation of $\mathrm{Ca}^{2+}$ channels could have a significant impact on synaptic transmission. In fact, the modulatory effect of syntaxin on synaptosomal $\mathrm{Ca}^{2+}$ influx can be substantial (up to $50 \%$ ), so the consequences for synaptic transmission could be striking. What role would this modulation play in nerve terminals? At the outset of this study, one possibility was that syntaxin might mediate a rapid form of communication to shut down $\mathrm{Ca}^{2+}$ entry at presynaptic sites. Modulation of presynaptic $\mathrm{N}$-type $\mathrm{Ca}^{2+}$ channels had already been hypothesized to help control synaptic refractoriness on a millisecond time scale (Dobrunz et al., 1997). An alternative possibility was that syntaxin might support slow signaling that reflects the average state of the release machinery over an extended period. Our experiments provided a starting point for assessing these possibilities. Based on the results illustrated in Figures 5 and 6, modulation of $\mathrm{Ca}^{2+}$ channels by syntaxin is an unlikely mechanism for short-term synaptic refractoriness. On the other hand, syntaxin regulation of $\mathrm{Ca}^{2+}$ influx seems well suited for control of synaptic strength over a span of tens of seconds or minutes. Along these lines, the functional relevance of slow inactivation of presynaptic $\mathrm{Ca}^{2+}$ 
channels has been demonstrated at a calyx synapse in the brainstem, where conventional depolarizing pulses or trains of brief pulses caused a long-lasting inactivation of presynaptic P-type channels and substantial post-tetanic depression of transmission (Forsythe et al., 1998). The inactivation was dependent on divalent cation entry and required 1-2 min for full recovery, in accord with the modulatory effects described here. Whether syntaxin actually participates in this modulation remains to be seen. Meanwhile, we find it particularly interesting that channel gating and vesicular turnover may both be required to initiate the syntaxin stabilization of the inactivated state. The stabilization would be most powerful during and after bouts of high activity and would link excitable membrane function to internal membrane trafficking.

\section{REFERENCES}

Adams ME, Mintz IM, Reily MD, Thanabal V, Bean BP (1993) Structure and properties of $\omega$-Agatoxin IVB, a new antagonist of P-type calcium channels. Mol Pharmacol 44:681-688.

Bergsman JB, Tsien RW (1996) Testing for botulinum toxin type C1 effect on calcium flux in rat neocortical synaptosomes. J Gen Physiol 108:9A.

Bezprozvanny I, Scheller RH, Tsien RW (1995) Functional impact of syntaxin on gating of N-type and Q-type calcium channels. Nature 378:623-626.

Blasi J, Chapman ER, Link E, Binz T, Yamasaki S, De Camilli P, Sudhof TC, Niemann H, Jahn R (1993a) Botulinum neurotoxin A selectively cleaves the synaptic protein SNAP-25 [see comments]. Nature 365:160-163.

Blasi J, Chapman ER, Yamasaki S, Binz T, Niemann H, Jahn R (1993b) Botulinum neurotoxin $\mathrm{C} 1$ blocks neurotransmitter release by means of cleaving HPC-1/syntaxin. EMBO J 12:4821-4828.

Blaustein MP, Goldring JM (1975) Membrane potentials in pinched-off presynaptic nerve terminals monitored with a fluorescent probe: evidence that synaptosomes have potassium diff usion potentials. J Physiol (Lond) 247:589-615.

Capogna M, McKinney RA, O'Connor V, Gähwiler BH, Thompson SM (1997) $\mathrm{Ca} 2+$ or $\mathrm{Sr} 2+$ partially rescues synaptic transmission in hippocampal cultures treated with botulinum toxin $\mathrm{A}$ and $\mathrm{C}$, but not tetanus toxin. J Neurosci 17:7190-7202.

Charvin N, L'Eveque C, Walker D, Berton F, Raymond C, Kataoka M, Shoji-Kasai Y, Takahashi M, De Waard M, Seagar MJ (1997) Direct interaction of the calcium sensor protein synaptotagmin I with a cytoplasmic domain of the alpha1A subunit of the P/Q-type calcium channel. EMBO J 16:4591-4596.

Degtiar VE, Scheller RH, Tsien RW (2000) Syntaxin modulation of slow inactivation of N-type calcium channels. J Neurosci 20: 4355-4367.

Dobrunz LE, Huang EP, Stevens CF (1997) Very short-term plasticity in hippocampal synapses. Proc Natl Acad Sci USA 94:14843-14847.

Dodge Jr F, Rahamimoff R (1967) Co-operative action of calcium ions in transmitter release at the neuromuscular junction. J Physiol (Lond) 193:419-432.

Douglas WW (1968) Stimulus-secretion coupling: the concept and clues from chromaffin and other cells. Br J Pharmacol 34:453-474.

el Far O, Charvin N, Leveque C, Martin-Moutot N, Takahashi M, Seagar MJ (1995) Interaction of a synaptobrevin (VAMP)-syntaxin complex with presynaptic calcium channels. FEBS Lett 361:101-105.

Fontana G, Blaustein MP (1993) Calcium buffering and free $\mathrm{Ca} 2+$ in rat brain synaptosomes. J Neurochem 60:843-850.

Foran P, Lawrence GW, Shone CC, Foster KA, Dolly JO (1996) Botulinum neurotoxin $\mathrm{C} 1$ cleaves both syntaxin and SNAP-25 in intact and permeabilized chromaffin cells: correlation with its blockade of catecholamine release. Biochemistry 35:2630-2636.

Forsythe ID, Tsujimoto T, Barnes-Davies M, Cuttle MF, Takahashi T (1998) Inactivation of presynaptic calcium current contributes to synaptic depression at a fast central synapse. Neuron 20:797-807.

Grynkiewicz G, Poenie M, Tsien RY (1985) A new generation of Ca2+ indicators with greatly improved fluorescence properties. J Biol Chem 260:3440-3450.

Katz B, Miledi R (1965) The effect of calcium on acetylcholine release from motor nerve terminals. Proc R Soc Lond B Biol Sci 161:496-503.

Kim DK, Catterall WA (1997) Ca2+-dependent and -independent in- teractions of the isoforms of the alpha1A subunit of brain $\mathrm{Ca} 2+$ channels with presynaptic SNARE proteins. Proc Natl Acad Sci USA 94:14782-14786.

Kleyman TR, Cragoe Jr EJ (1988) Amiloride and its analogs as tools in the study of ion transport. J Membr Biol 105:1-21.

Kosaka T, Ikeda K (1983) Possible temperature-dependent blockage of synaptic vesicle recycling induced by a single gene mutation in Drosophila. J Neurobiol 14:207-225.

Llinás R, Steinberg IZ, Walton K (1981) Relationship between presynaptic calcium current and postsynaptic potential in squid giant synapse. Biophys J 33:323-351.

Marsal J, Ruiz-Montasell B, Blasi J, Moreira JE, Contreras D, Sugimori M, Llinás R (1997) Block of transmitter release by botulinum C1 action on syntaxin at the squid giant synapse. Proc Natl Acad Sci USA 94:14871-14876.

Martin-Moutot N, Charvin N, Leveque C, Sato K, Nishiki T, Kozaki S, Takahashi M, Seagar M (1996) Interaction of SNARE complexes with $\mathrm{P} / \mathrm{Q}$-type calcium channels in rat cerebellar synaptosomes. J Biol Chem 271:6567-6570.

Mastrogiacomo A, Parsons SM, Zampighi GA, Jenden DJ, Umbach JA, Gundersen CB (1994) Cysteine string proteins: a potential link between synaptic vesicles and presynaptic $\mathrm{Ca} 2+$ channels. Science 263:981-982.

McMahon HT, Nicholls DG (1991) Transmitter glutamate release from isolated nerve terminals: evidence for biphasic release and triggering by localized $\mathrm{Ca} 2+$. J Neurochem 56:86-94.

McMahon HT, Foran P, Dolly JO, Verhage M, Wiegant VM, Nicholls DG (1992) Tetanus toxin and botulinum toxins type A and B inhibit glutamate, gamma-aminobutyric acid, aspartate, and met-enkephalin release from synaptosomes. Clues to the locus of action. J Biol Chem 267:21338-21343.

Meder W, Fink K, Göthert M. (1997) Involvement of different calcium channels in $\mathrm{K}+-$ and veratridine-induced increases of cytosolic calcium concentration in rat cerebral cortical synaptosomes. Naunyn Schmiedebergs Arch Pharmacol 356:797-805.

Mochida S, Saisu H, Kobayashi H, Abe T (1995) Impairment of syntaxin by botulinum neurotoxin $\mathrm{C} 1$ or antibodies inhibits acetylcholine release but not $\mathrm{Ca} 2+$ channel activity. Neuroscience 65:905-915.

Mochida S, Sheng ZH, Baker C, Kobayashi H, Catterall WA (1996) Inhibition of neurotransmission by peptides containing the synaptic protein interaction site of N-type Ca2+ channels. Neuron 17:781-788.

Montecucco C, Schiavo G (1995) Structure and function of tetanus and botulinum neurotoxins. Q Rev Biophys 28:423-472.

Neher E (1995) The use of fura-2 for estimating Ca buffers and Ca fluxes. Neuropharmacology 34:1423-1442.

Neher E, Augustine GJ (1992) Calcium gradients and buffers in bovine chromaffin cells. J Physiol (Lond) 450:273-301.

Newcomb R, Szoke B, Palma A, Wang G, Chen X, Hopkins W, Cong R, Miller J, Urge L, Tarczy-Hornoch K, Loo JA, Dooley DJ, Nadasdi L, Tsien RW, Lemos J, Miljanich G (1998) Selective peptide antagonist of the class E calcium channel from the venom of the tarantula Hysterocrates gigas. Biochemistry 37:15353-15362.

Nicholls DG, Sihra TS, Sanchez-Prieto J (1987) Calcium-dependent and -independent release of glutamate from synaptosomes monitored by continuous fluorometry. J Neurochem 49:50-57.

Niemann H, Blasi J, Jahn R (1994) Clostridial neurotoxins: new tools for dissecting exocytosis. Trends Cell Biol 4:179-185.

O'Connor V, Heuss C, De Bello WM, Dresbach T, Charlton MP, Hunt JH, Pellegrini LL, Hodel A, Burger MM, Betz H, Augustine GJ, Schäfer T (1997) Disruption of syntaxin-mediated protein interactions blocks neurotransmitter secretion. Proc Natl Acad Sci USA 94:12186-12191.

Patil PG, Brody DL, Yue DT (1998) Preferential closed-state inactivation of neuronal calcium channels. Neuron 20:1027-1038.

Pupier S, Leveque C, Marqueze B, Kataoka M, Takahashi M, Seagar MJ (1997) Cysteine string proteins associated with secretory granules of the rat neurohypophysis. J Neurosci 17:2722-2727.

Raciborska DA, Trimble WS, Charlton MP (1998) Presynaptic protein interactions in vivo: evidence from botulinum $\mathrm{A}, \mathrm{C}, \mathrm{D}$ and $\mathrm{E}$ action at frog neuromuscular junction. Eur J Neurosci 10:2617-2628.

Ramaswami M, Krishnan KS, Kelly RB (1994) Intermediates in synaptic vesicle recycling revealed by optical imaging of Drosophila neuromuscular junctions. Neuron 13:363-375.

Randall A, Tsien RW (1995) Pharmacological dissection of multiple 
types of $\mathrm{Ca} 2+$ channel currents in rat cerebellar granule neurons. J Neurosci 15:2995-3012.

Rettig J, Sheng ZH, Kim DK, Hodson CD, Snutch TP, Catterall WA (1996) Isoform-specific interaction of the alpha1A subunits of brain $\mathrm{Ca} 2+$ channels with the presynaptic proteins syntaxin and SNAP-25. Proc Natl Acad Sci USA 93:7363-7368.

Rettig J, Heinemann C, Ashery U, Sheng ZH, Yokoyama CT, Catterall WA, Neher E (1997) Alteration of Ca2+ dependence of neurotransmitter release by disruption of $\mathrm{Ca} 2+$ channel/syntaxin interaction. J Neurosci 17:6647-6656.

Schiavo G, Benfenati F, Poulain B, Rossetto O, Polverino de Laureto P, DasGupta BR, Montecucco C (1992) Tetanus and botulinum-B neurotoxins block neurotransmitter release by proteolytic cleavage of synaptobrevin [see comments]. Nature 359:832-835.

Schiavo G, Shone CC, Bennett MK, Scheller RH, Montecucco C (1995) Botulinum neurotoxin type $\mathrm{C}$ cleaves a single Lys-Ala bond within the carboxyl-terminal region of syntaxins. J Biol Chem 270:10566-10570.

Sheng ZH, Rettig J, Takahashi M, Catterall WA (1994) Identification of a syntaxin-binding site on N-type calcium channels. Neuron 13:1303-1313.

Sheng ZH, Rettig J, Cook T, Catterall WA (1996) Calcium-dependent interaction of $\mathrm{N}$-type calcium channels with the synaptic core complex. Nature 379:451-454.

Sheng ZH, Yokoyama CT, Catterall WA (1997) Interaction of the synprint site of $\mathrm{N}$-type $\mathrm{Ca} 2+$ channels with the $\mathrm{C} 2 \mathrm{~B}$ domain of synaptotagmin I. Proc Natl Acad Sci USA 94:5405-5410.

Smirnova T, Fossier P, Stinnakre J, Mallet J, Baux G (1995) A syntaxinrelated protein controls acetylcholine release by different mechanisms in Aplysia. Neuroscience 68:125-133.

Stanley EF, Mirotznik RR (1997) Cleavage of syntaxin prevents G-protein regulation of presynaptic calcium channels. Nature 385:340-343.

Sugimori M, Tong CK, Fukuda M, Moreira JE, Kojima T, Mikoshiba K, Llinás R (1998) Presynaptic injection of syntaxin-specific antibodies blocks transmission in the squid giant synapse. Neuroscience 86:39-51.

Sutton RB, Fasshauer D, Jahn R, Brunger AT (1998) Crystal structure of a SNARE complex involved in synaptic exocytosis at 2.4 A resolution [see comments]. Nature 395:347-353.

Teramoto T, Kuwada M, Niidome T, Sawada K, Nishizawa Y, Katayama K (1993) A novel peptide from funnel web spider venom, omega-AgaTK, selectively blocks, P-type calcium channels. Biochem Biophys Res Commun 196:134-140.
Tibbs GR, Barrie AP, Van Mieghem FJ, McMahon HT, Nicholls DG (1989) Repetitive action potentials in isolated nerve terminals in the presence of 4-aminopyridine: effects on cytosolic free $\mathrm{Ca} 2+$ and glutamate release. J Neurochem 53:1693-1699.

Tibbs GR, Dolly JO, Nicholls DG (1996) Evidence for the induction of repetitive action potentials in synaptosomes by $\mathrm{K}+$-channel inhibitors: an analysis of plasma membrane ion fluxes. J Neurochem 67:389-397.

Umbach JA, Saitoe M, Kidokoro Y, Gundersen CB (1998) Attenuated influx of calcium ions at nerve endings of csp and shibire mutant Drosophila. J Neurosci 18:3233-3240.

Vance CL, Begg CM, Lee WL, Dubel SJ, Copeland TD, Sönnichsen FD, McEnery MW (1999) N-type calcium channel/syntaxin/SNAP-25 complex probed by antibodies to II-III intracellular loop of the alpha1B subunit. Neuroscience 90:665-676.

Verhage M, Ghijsen WE, Nicholls DG, Wiegant VM (1991) Characterization of the release of cholecystokinin-8 from isolated nerve terminals and comparison with exocytosis of classical transmitters. J Neurochem 56:1394-1400.

Verhage M, Hens JJ, De Grann PN, Boomsma F, Wiegant VM, da Silva FH, Gispen WH, Ghijsen WE (1995) Ba2+ replaces Ca2+/calmodulin in the activation of protein phosphatases and in exocytosis of all major transmitters. Eur J Pharmacol 291:387-398.

Williamson LC, Halpern JL, Montecucco C, Brown JE, Neale EA (1996) Clostridial neurotoxins and substrate proteolysis in intact neurons: botulinum neurotoxin $\mathrm{C}$ acts on synaptosomal-associated protein of 25 kDa. J Biol Chem 271:7694-7699.

Wiser O, Bennett MK, Atlas D (1996) Functional interaction of syntaxin and SNAP-25 with voltage-sensitive $\mathrm{L}$ - and $\mathrm{N}$-type $\mathrm{Ca} 2+$ channels. EMBO J 15:4100-4110.

Wiser O, Trus M, Hernandez A, Renstrom E, Barg S, Rorsman P, Atlas D (1999) The voltage sensitive Lc-type Ca2+ channel is functionally coupled to the exocytotic machinery. Proc Natl Acad Sci USA 96:248-253.

Wu LG, Borst JG, Sakmann B (1998) R-type Ca2+ currents evoke transmitter release at a rat central synapse. Proc Natl Acad Sci USA 95:4720-4725.

Yokoyama CT, Sheng ZH, Catterall WA (1997) Phosphorylation of the synaptic protein interaction site on N-type calcium channels inhibits interactions with SNARE proteins. J Neurosci 17:6929-6938.

Zhong H, Yohoyama CT, Scheuer T, Catterall WA (1999) Reciprocal regulation of $\mathrm{P} / \mathrm{Q}$-type $\mathrm{Ca} 2+$ channels by SNAP-25, syntaxin and synaptotagmin. Nature 2:939-941. 